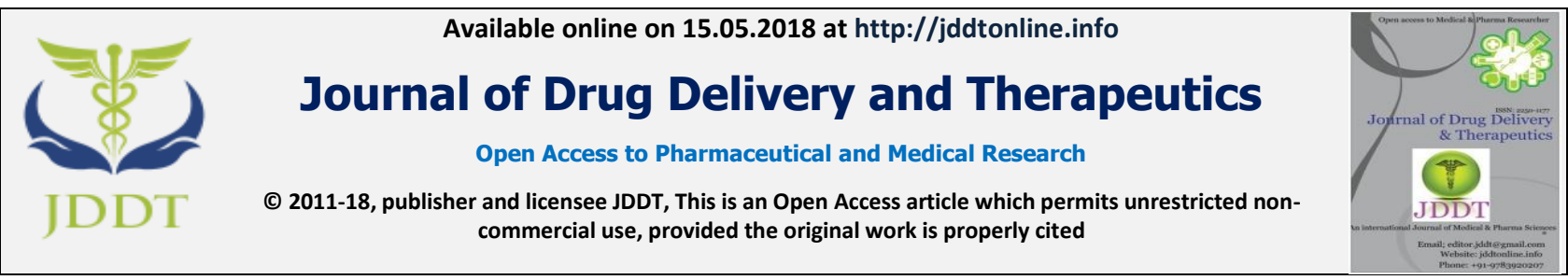

Open $\odot$ Access

Review Article

\title{
SCOPE OF PHARMACIST ON FUTURE ASPECT
}

\author{
Sanskriti Tripathi", Md Shariq Ansari, Kaseem Ahmad, Haider Ali, Ruby Tabassum, Dilip K. Patel \\ Chandra Shekhar Singh College of Pharmacy, Kausambi, Allahabad, U.P. India
}

\begin{abstract}
Pharmacy is a profession started in India early in 20th Century. Since then, it has undergone many changes educationally and professionally. The Profession of Pharmacy is Associate in Nursing integral a part of the aid system worldwide. Pharmacies are a well-organized follow will go an extended way to ensure quality health care for the patient. In past, pharmacists were answerable for dispensing medications solely. Slowly, the normal role of pharmacists is increasing and currently pharmacists are enjoying a significant role team member within the direct care of patients, especially the new generation pharmacists World Health Organization have Pharm. D. in the future, innovations in the discovery and development of newer medicine and dosage forms are used and personalized pharmacotherapy are propagated. The future pharmacist needs to bear in mind of those developments to advise the doctor and the patient to be a competent partner within the health care team. At the same time, the drug restrictive authorities in Republic of India and medical professionals have to be compelled to recognize the contribution of the pill pusher to society. Only then can the noble pharmacy profession be able to reach the level of greatness it deserves.
\end{abstract}

Keywords: druggist, India, patient counseling, future, and unemployment.

Article Info: Received 20 Jan, 2018; Review Completed 31 March 2018; Accepted 02 April 2018; Available online 15 May 2018

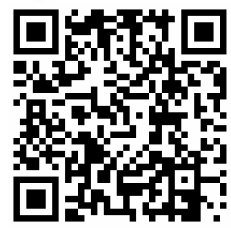

Cite this article as:

Tripathi S, Ansari MS, Ahmad K, Ali H, Tabassum R, Patel DK, Scope of pharmacist on future aspect, Journal of Drug Delivery and Therapeutics. 2018; 8(3):133-137 DOI: http://dx.doi.org/10.22270/jddt.v8i3.1691

*Address for Correspondence:

Sanskriti Tripathi, Chandra Shekhar Singh College of Pharmacy, Kausambi, Allahabad, U.P. India

\section{INTRODUCTION}

A pharmacist may be a one who is concerned in planning, making or producing of a drug product, dispensing of a drug, managing, and coming up with of a pharmaceutical care set up. They're specialists on the action and uses of medicine, together with their chemistry, materia medica, the formulation of medicines. they're the health care professionals World Health Organization have the responsibility to supply medical aid to the patients and providing safe and effective use of medicines. ${ }^{1}$ Among doctors/physicians and nurses, pharmacists also are a part of the constellation of the health care system that has the first role to satisfy the patient's want and to reduce their issues relating to any illness. There's range of how wherever a pill roller will perform his/her role. He/She will be a part of associate business wherever he is a production or internal control officer, could involve in restrictive affairs, or do sales and selling of a replacement drug. Additionally, he/she will involve in analysis and development program. In terms of clinical settings, a pill roller will add a hospital as either a hospital pharmacist and might be a clinical pill roller wherever they will work directly with the overall practitioners as a part of the core team. The opposite domain is world wherever a pharmacist is concerned in teaching and academic-related activities. A community pharmacist, conjointly coined as a retail pill roller, dispensing pharmacist, maybe a one who counsels, dispenses and manages the patients care to set up. because the community pharmacists square measure in direct contact with the patient in order that they have a variety of responsibilities which may facilitate to boost the vision of their profession and their want during this health care system setting. If they need to be identified in order that they will build the boldness among patients and it'd be a key supply by that patients begin to stick to their medical care and begin to trust them. He conjointly concerned in reducing patient's price and provides a secure and effective medical care. ${ }^{2,3}$ 


\section{CURRENT SCENARIO OF PHARMACIST}

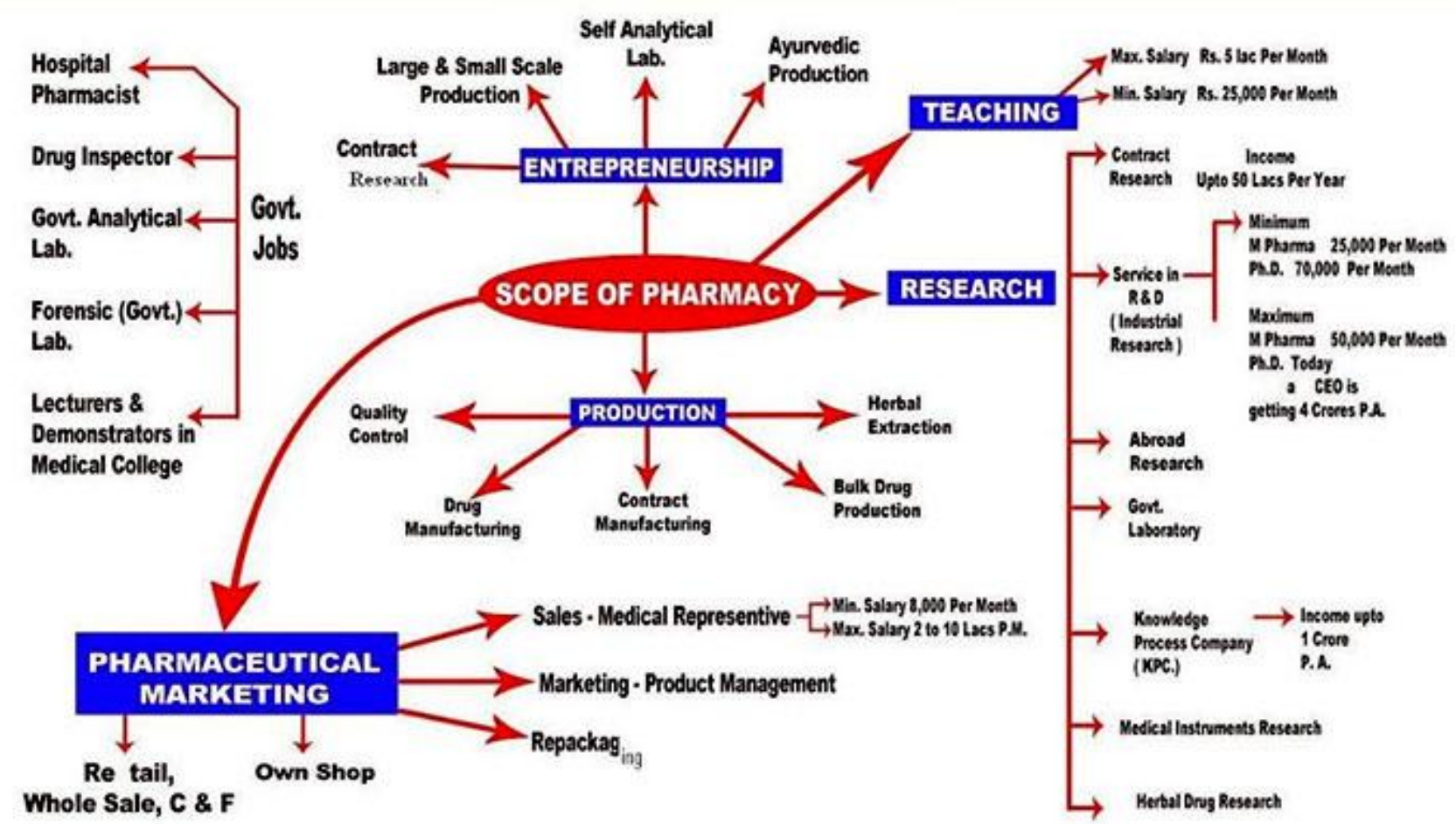

Fig1: Scope of pharmacy[http://www.cuchd.in/pharma-sciences/images/scope-of-pharmacy.jpg]

\section{IN A HOSPITAL, TEACHERS AND ANY EDUCATION}

As a medico is thought for surgery, a medico is thought for designation and treatment of a disease; a CP would be known/recognized for providing cycles/second in Bharat. Providing cycles/second is that the 1 st and foremost responsibility of a CP. cycles/second will work as a college member in an educational institute. they will additionally be part of an appropriate teaching position in an exceedingly Diploma/Degree/Postgraduate Pharmacy Institute like a lecturer, professor, professor, professor, head of the department, head of the establishment, principal or director with appropriate expertise. At now of your time, various PharmD faculties have gotten established in Bharat, so both $\mathrm{M}$. Pharm (Pharmacy Practice) and PharmD folks have giant job prospectuses in lecturers. As so much as nonteaching hospitals square measure thought-about, currently, some elite and US-based hospitals in India square measure recruiting cycles/second. Active pharmacist's square measure expected to be recruited by the govt. hospitals too in close to future. Moreover, cycles/second might have a task in hospital administration team, pharmacy/therapeutic committees in hospital etc. ${ }^{4}$

\section{HIGHER EDUCATION}

The one that has completed Phar.D. /M. Pharm (Pharmacy Practice/Clinical Pharmacy) will register for
Ph.D. in India/abroad. After Phar.D., some western countries provide specialty programs like medical specialty, pharmacotherapy, nuclear pharmacy, nutrition support, psychiatry, ambulant care, etc. Such specialty courses don't seem to be nonetheless obtainable in Bharat, however, would be gettable in so much future. ${ }^{5}$

\section{CLINICAL PHARMACIST}

Clinical pharmacists work directly with physicians, different health professionals, and patients to confirm that the medications prescribed for patients contribute to the most effective doable health outcomes. Clinical pharmacists apply in health care settings wherever they need frequent and regular interactions with physicians and different health professionals, causative to higher coordination of care. ${ }^{6}$

The clinical caregiver is educated and trained in direct patient care environments, as well as medical centers, clinics, and a spread of different aid settings. Clinical pharmacists square measure oft granted patient care privileges by collaborating physicians and/or health systems that permit them to perform a full vary of medication decision-making functions as a part of the patient's aid team. These privileges square measure granted on the premise of the clinical pharmacist's incontestable data of medication medical care and record of clinical expertise. This specialized data and clinical expertise square measure sometimes gained through residency coaching and specialty board certification. ${ }^{7}$ 


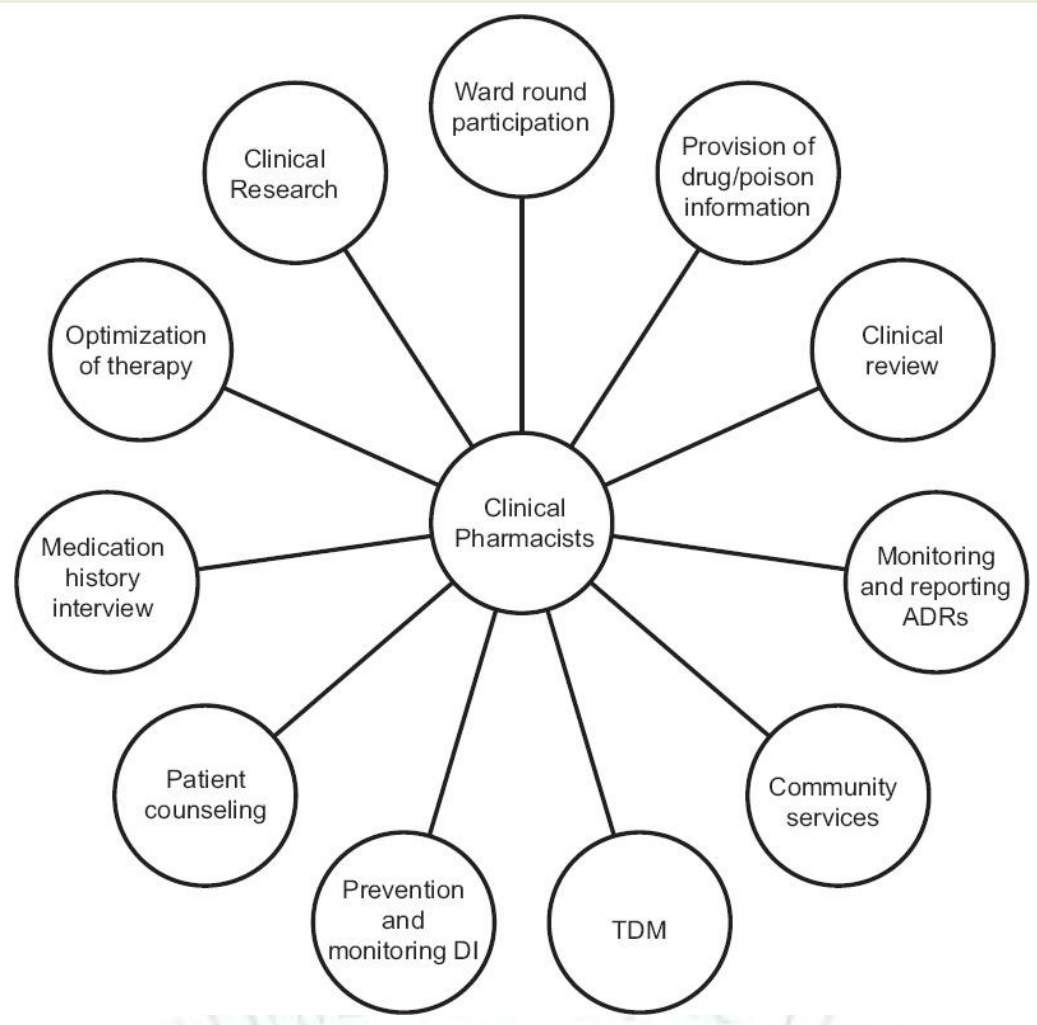

Figure 2: Hospital activities of clinical pharmacists (ADR: Adverse drug reactions; DI: Drug interactions; TDM: Therapeutic drug monitoring)

\section{MEDICAL WRITING}

This is additionally called "scientific writing" or "medical communications". Medical writing involves writing different kinds of attention documents for a special purpose and for various audiences. The medical writers square measure needed in pharmaceutical/healthcare firms, contract analysis organizations (CROs), Business method Outsourcing/Knowledge method Outsourcing firms (BPOs/KPOs), attention communication firms, media and publication firms, medical journals, medical societies etc., the talents required to become a competent medical author are: Domain information, language and synchronic linguistics skills, fast interpretation of medical information etc. At present, there square measure varied CROs, BPOs, KPOs and pharmaceutical firms in Asian country United Nations agency square measure hiring medical writers. ${ }^{8}$

\section{MEDICAL CODING}

Medical cryptography (also called medical classification) is nothing, however, the transformation of descriptions of medical diagnoses and procedures into universally acceptable codes. The codes square measure employed in a range of fields like medication, public health and medical scientific discipline for applied math analysis, compensation schemes, etc., currently, their square measure varied medical cryptography firms in the Asian country. ${ }^{9}$

\section{MEDICAL BILLING}

The medical request is completely different from medical cryptography. it's the method of translation of attention service into request claim. There square measure several insurance firms within the nation, however, to the most effective our information, enlisting of rate is incredibly abundant rare at this time. However, we have a tendency to project the role of the rate in medical request likewise. ${ }^{10}$

\section{MEDICAL TRANSCRIPTION}

In easy language, medical transcription is transcribing (typing) the doctor's reports from settled audio files. In developed countries, the health professional person dictates what he has done once playacting procedures on the patient and also the medical transcriptionist (MT) (also called medical language specialist) transcribes the oral dictations and/or edits the reports. Such patientspecific health info is born-again in an exceeding transcription document and maintained in written, Eversion or unbroken inpatient record files. Nowadays, speech recognition package is employed for the higher follow of medical transcriptions.

Medical transcriptionists could also be employed by the hospital or the work could also be outsourced. At present, numberless medical transcription firms square measure accessible in the Asian country. within the current state of affairs, there square measure restricted hospitals in Asian country recruiting MTs. Skills required to become associate MT embody Sound information of medical terminologies, unwellness conditions, anatomy, physiology, pharmacology; medical language and grammar; writing skills; effective communication skills, etc. ${ }^{10-12}$

\section{PHARMACOVIGILANCE}

World Health Organization defines pharmacovigilance as, "the science and activities about the detection, 


\section{Tripathi et al}

assessment, understanding, and bar of adverse effects or the other drug-related problem".

Documentation, analysis, and a bar of ADRs square measure required for medical specialty studies and patient safety. Presently, some hospitals in Asian country square measure recruiting peoples in pharmacovigilance. Varied BPOs/KPOs in Asian country square measure recruiting individuals for pharmacovigilance. Skills required to figure within the space of pharmacovigilance square measure Sound information of pharmacological medicine and ADRs, laboratory results, clinical analysis etc. ${ }^{12}$

\section{CLINICAL RESEARCH AND DRUG DEVELOPMENT}

Both this stuff square measure associated with clinical trials. There square measure numberless clinical analysis organizations gift within the country. Clinical analysis arranger, clinical analysis associate (CRAs), analysis statisticians and better positions (with optimum experience) square measure appropriate posts for the rate in clinical analysis organizations. the rate will even work as principal investigators ${ }^{41}$ and patient educators in clinical trials. Pharmacists will play a job in enhancing patient participation in the trial analysis. Skills required to figure clinical analysis organization embody information of applied math, medical and pharmacological terms, pharmacovigilance, sincerity within the documentation, ability to travel extensively (especially for CRAs) etc. ${ }^{8}$

\section{FORENSIC PHARMACY}

Forensic pharmacy is that the field wherever there's the appliance of drug-sciences to medico-legal problems. In western countries, a caregiver will have interaction in legal cases associated with malpractice, ADRs, drunk driving, drug abuse, attention fraudulence, poisoning/toxicity, and varied different sorts of civil and criminal cases. although Asian country has only a few pharmacists operating in these areas at now of your time, we have a tendency to believe that rate can have future in these areas too. ${ }^{1,4}$

\section{MEDICAL/CLINICAL SCIENCE LIAISON}

Medical science liaison (MSL) is also a attention consulting accomplished utilized by pharmaceutical, biotechnology, medical device and managed care corporations to supply unbiased (nonpromotional) information concerning the merchandise.

- Ensures that merchandise unit of measurement used effectively

- Serves as scientific peers and resources among the health profession

- Serves as scientific consultants to internal colleagues at companies. ${ }^{13}$

\section{CONTRACT ANALYSIS ORGANIZATIONS}

Contract analysis organizations unit of measurement a company that has support to the product/device (pharmaceutical/biotechnological/medical) among the kind of research services on contract basis. the speed would possibly get absorbed in CROs in operation
Journal of Drug Delivery \& Therapeutics. 2018; 8(3): 133-137

among the subsequent fields - pharmacoeconomics, patient-reported outcomes, health technology assessment, literature reviews, systematic reviews, quality of life studies etc. of those sq. measures square measure new in Associate in Nursing land, however, such CROs do exist among the country. The talent needed to work in CROs is nice analytical skills, thorough data of medication and statistics, superb grasping capability, handling of databases (e.g., PubMed), etc. ${ }^{7,9,10}$

\section{BUSINESS OPPORTUNITIES AND MARKET RESEARCH}

With correct market data, expertise and investment, a CP will begin a business with any of the ideas mentioned higher than. As they'll analyze the comparative effectualness and distinctive marketing property of the medicine, Hertz even have a task in product management team, research, and medicomarketing. ${ }^{2,3}$

\section{BIOAVAILABILITY/BIOEQUIVALENCE STUDIES}

In easy words, bioavailability (BA) is that the fraction of the administered drug offered within the blood circulation whereas bioequivalence (BE) is that the comparison bioavailabilities of 2 pharmaceutical product with same drug and indefinite quantity. BA/BE studies square measure conducted for following necessary purposes(1) development and determination of dose and indefinite quantity type of a drug (2) internal control of drug product (3)development of a brand new formulation of the present medicine. The businesses operating within the space of BA/BE exist in the Asian nation. To enter the field of $\mathrm{BA} / \mathrm{BE}$ studies, data of pharmacotherapeutics, clinical materia medica, and clinical analysis is critical. ${ }^{8}$

\section{PUBLIC HEALTH, GOVERNMENT SECTOR, AND NONGOVERNMENTAL ORGANIZATION}

Apart from community pharmacy, the pharmacists do have a task publically health. The square measures and therefore the role of pharmacists are as follows:

- Immunization programs: Administration and promotion of immunization

- Disaster readiness and response, e.g., natural disaster: Education of public, coming up with of emergency response, police investigation of inform syndromes conditions, communication with public, provision of mass medications, etc.

- Contraceptive services: Distribution of contraceptive measures and education regarding their use

- Prevention and management of illness and injury: Promotion of healthy lifestyles cut back hospitalizations. ${ }^{6}$

\section{PRODUCTION}

Production/manufacture of bulk medicine \& intermediates, finished medicines, vaccines biological product, veterinary medicines, Ayurvedic medicines, diagnostic product $\&$ medical devices. ${ }^{13}$ 


\section{PACKAGING}

Packaging is that the science, art, and technology of enclosure or protective product for distribution, storage, sell, and use. The packaging conjointly refers to the method of coming up with, evaluating, and manufacturing packages. Packaging will be delineated as a coordinated system of getting the ready product for transport, reposting, logistics, sale, and finish used. Packaging contains, protects, preserves, transports, informs and sells. ${ }^{1}$ In several countries, it's absolutely integrated into government, business, and institutional, industrial, and private use. ${ }^{14}$

\section{QUALITY MANAGEMENT}

Product testing throughout the life cycle of the drug and finished product (from raw materials, material to finished goods/stability, etc.) ${ }^{14}$

\section{REGULATORY AFFAIRS}

Regulatory affairs could be a relatively new profession that developed from the will of governments to guard public health by dominant the security and effectualness of product in areas together with prescribed drugs, veterinary medicines, medical devices, pesticides, agrochemicals, cosmetics and complementary medicines. $^{14}$

\section{CONCLUSION}

The pill roller with Pharm D or M.Pharm will function an important supply of drug info or polypharmacy for the medico, nurses, alternative aid professionals, and patients; maybe the sole skilled WHO will facilitate within the reduction of drug-related issues and drug interactions, providing efficient medical care and deciding drug-related effects on blood biochemistry. ${ }^{13}$

\section{REFRENCES}

1. Tharappel LJP, Kaur G, "Pharmaceutical Education in India: past, present, and future" journal of pharmaceutical sciences and research, ISSN: 0975-1459

2. Manasse, Jr. HR, Speedie MK. Pharmacists, pharmaceuticals, and policy issues shaping the workforce in pharmacy. Am J Pharm Educ. 2007; 71(5):82. Available at: http://www.ncbi.nlm.nih.gov/pmc/articles/PM 2064880/pdf/ ajpe82.pdf. Accessed July 9, 2010.

3. Kloss H., Chama T., Abemo D., Tsadik K. G. and Belay S.. Utilization of pharmacies and pharmaceutical drugs in Adis Ababa, Ethiopia. Soc. Sci. Med. 1986; Vol. 22, pp 653.

4. Hawksworth GM, Chrystyn H. Clinical pharmacy in primary care. Br J Clin Pharmacol. 1998; 46(5):415-20.

5. Dhote vinod, SC Mahajan and K.M. Dinesh, "opportunities and challenge in pharmacy profession in developing countries like India: an overview" journal der pharmazie orschung 2013

6. Adnan shazia, Atta Abbas, Tanwir Sidra, "The role and scope of pharmacists in community settings: A review of developing countries" IJAMSCR, 2014; 2(1):32-35

7. Van der Geest S. The illegal distribution of western medicines in developing countries: pharmacist, drug peddlers, injection doctors and others: a bibliographic exploration. Med. Anthropol. 1982; Vol. 6, pp 197.
For instance, in a very case wherever there's the coincidental administration of agonists or antagonists, the pharmacist will play an important role by providing info regarding the suitable dose to achieve the utmost possible therapeutic impact of the co-administered medicines. Moreover, in treating geriatric and medical patients with polypharmacy problems, the pill roller will play a significant role in medical care compliance and improving quality of life through effective counseling sessions. Also, among patients with chronic ailments like diabetes, asthma attack, high blood pressure, lipoidemia, pathology, psychotic disorders, and alternative infectious diseases, the pill roller will improve medical care outcomes and physical well-being via medication medical care management. ${ }^{2,13}$ Several studies have demonstrated that intrinsic and adscititious factors area unit valid and area unit vital variables to contemplate once evaluating job satisfaction among pharmacists. Intrinsic factors like challenge, performance, and autonomy; and adscititious factors like rewards, salary, benefits, job atmosphere, advancement, and management issues area unit significant and major predictors of job satisfaction. More study of those variables by a multidisciplinary team will improve levels of job satisfaction among Indian pharmacists. The govt policymakers ought to implement policies supported the intrinsic and adscititious factors to lift worker satisfaction within the geographical point. Pharmacy and medical (drug related) authorities ought to additionally at the state and native level, undertake initiatives to reinforce the role of pharmacists in each community settings and hospitals to boost the therapeutic outcomes for patients, generate and improve pill roller job satisfaction, and improve health and medication-related awareness among folks.

8. Mills A. and Walker G. J. A. Drugs for the poor, 1988Third World: consumption and distribution. J. Trop.Med. Hygiene 1983; Vol. 86, issue 139.

9. Logan K.The role of pharmacists and over the counter medications in the health care system of a Mexican city. Med. Anthropol. 1983; Vol. 7, issue 68.

10. Igun U. A.Why we seek treatment here: retail pharmacy and clinical practice in Maiduguri. Nigeria. Soc.Sci. Med. V1987; ol. 24, pp 689.

11. Michael D Rawlins. Extending the role of the community pharmacist Depends on extending training and regulation. vol: BMJ, 1991; Vol. 302, issue 23

12. Hayashi $\mathrm{S}$ and Yakugaku Zasshi. The expected role of community pharmacist in society. Journal of the Pharmaceutical Society of Japan. 2003; 123(3):163-171. PMID: 12693017

13. R.R.Reddy. 2010. Pharmacy sector in India set for a boom, feel experts. [News article]. [Online]. The Hindu. [Internet]. [Cited Dec 2013]. Retrieved from: http://www.hindu.com/ edu/2010/10/04/stories/2010100450440400.htm

14. Timothy McPherson and Patrick Fontane. Pharmacists' social authority to transform community pharmacy practice. 2011; Vol. 2, No. 2, 42. 